\title{
Mortality among subjects with chronic obstructive pulmonary disease or asthma at two respiratory disease clinics in Ontario
}

\author{
Murray M Finkelstein PhD MD CCFP1, Kenneth R Chapman MD MSc FRCPC ${ }^{2}$, \\ R Andrew Mclvor MD FRCPC ${ }^{3}$, Malcolm R Sears MB FRACP FRCPC ${ }^{3}$
}

MM Finkelstein, KR Chapman, RA McIvor, MR Sears. Mortality among subjects with chronic obstructive pulmonary disease or asthma at two respiratory disease clinics in Ontario. Can Respir J $2011 ; 18(6): 327-332$.

BACKGROUND: Chronic obstructive pulmonary disease (COPD) and asthma are common; however, mortality rates among individuals with these diseases are not well studied in North America.

OBJECTIVE: To investigate mortality rates and risk factors for premature death among subjects with COPD.

METHODS: Subjects were identified from the lung function testing databases of two academic respiratory disease clinics in Hamilton and Toronto, Ontario. Mortality was ascertained by linkage to the Ontario mortality registry between 1992 and 2002, inclusive. Standardized mortality ratios were computed. Poisson regression of standardized mortality ratios and proportional hazards regression were performed to examine the multivariate effect of risk factors on the standardized mortality ratios and mortality hazards.

RESULTS: Compared with the Ontario population, all-cause mortality was approximately doubled among subjects with COPD, but was lower than expected among subjects with asthma. The risk of mortality in patients with COPD was related to cigarette smoking, to the presence of comorbid conditons of ischemic heart disease and diabetes, and to Global initiative for chronic Obstructive Lung Disease severity scores. Individuals living closer to traffic sources showed an elevated risk of death compared with those who lived further away from traffic sources.

CONCLUSIONS: Mortality rates among subjects diagnosed with COPD were substantially elevated. There were several deaths attributed to asthma among subjects in the present study; however, overall, patients with asthma demonstrated lower mortality rates than the general population. Subjects with COPD need to be managed with attention devoted to both their respiratory disorders and related comorbidities.

Key Words: Asthma; Cohort study; COPD; Mortality; Risk factors hronic obstructive pulmonary disease (COPD) and asthma are common in Canada and around the world. In 2005, the prevalence of physician-diagnosed COPD exceeded 7\% among both men and women 65 years of age or older, while the prevalence of physiciandiagnosed asthma exceeded $8 \%$ among Canadians 12 years of age or older (1). Hill et al (2) recently reported a COPD prevalence of $21 \%$ among at-risk subjects, recruited from three Ontario primary care practices, who were 40 years of age or older and who had a smoking history of at least 20 pack-years. In a Polish primary care practice, the prevalence of COPD was $9.3 \%$ among patients 40 years of age or older (3). COPD is the fourth leading cause of mortality internationally, accounting for nearly three million deaths annually, and is the only major cause of mortality that is increasing in both developed and developing countries (4). In 2004, approximately 5\% of deaths in Canada were attributed to COPD. Mortality follow-up of COPD patients has been reported only once in Canada. Anthonisen et al (5) recruited 985 patients with COPD, treated them in a standard fashion and followed them closely for three years (5). Overall mortality was
La mortalité chez les sujets atteints d'une maladie pulmonaire obstructive chronique ou d'asthme dans deux cliniques de maladies respiratoires de l'Ontario

HISTORIQUE : La maladie pulmonaire obstructive chronique (MPOC) et l'asthme sont courants, mais le taux de mortalité chez les personnes qui en sont atteintes n'a pas tellement fait l'objet d'études en Amérique du Nord.

OBJECTIF : Examiner les taux de mortalité et les facteurs de risque de décès prématurés chez les personnes atteintes d'une MPOC.

MÉTHODOLOGIE : Les chercheurs ont répertorié les sujets dans des bases de données d'explorations fonctionnelles respiratoires de deux cliniques universitaires de maladies pulmonaires de Hamilton et de Toronto, en Ontario. Ils ont déterminé les décès en faisant des recoupements avec le registre des décès de l'Ontario entre 1992 et 2002, inclusivement. Ils ont calculé le ratio standardisé de mortalité. Ils ont aussi calculé le coefficient de régression de Poisson des ratios standardisés de mortalité et les coefficients de régression des hasards proportionnels pour examiner l'effet multivarié des facteurs de risque sur les ratios standardisés de mortalité et les risques de mortalité.

RÉSULTATS : Par rapport à la population de l'Ontario, la mortalité toutes causes confondues était environ deux fois plus élevée chez les sujets atteints d'une MPOC, mais plus faible que prévu chez les sujets atteints d'asthme. Le risque de mortalité chez les patients atteints d'une MPOC était lié au tabagisme, à la présence de maladies comorbides, tels que les maladies cardiaques ischémiques et le diabète, et aux indices de gravité de la Global Initiative for Chronic Obstructive Lung Disease. Les personnes qui habitaient plus près de sources de circulation présentaient un risque de décès élevé par rapport à celles qui en étaient plus éloignées.

CONCLUSIONS : Le taux de mortalité chez les sujets ayant une MPOC diagnostiquée était très élevé. Plusieurs décès étaient attribués à l'asthme chez les sujets participant à la présente étude, mais dans l'ensemble, les patients atteints d'asthme présentaient un taux de mortalité plus faible que celui de la population générale. Dans le cadre de la prise en charge des sujets atteints d'une MPOC, il faut s'attarder à la fois sur leurs troubles respiratoires et sur leurs comorbidités.

$23 \%$. Deaths attributable to asthma are relatively uncommon, averaging approximately 300 per year in Canada during the period spanning 2000 to 2004 (1).

Follow-up of subjects with respiratory diseases sheds light on mortality risks and may provide clues to the prevention of premature death. An American study (6) found that the Global initiative for chronic Obstructive Lung Disease (GOLD) classification of lung disease predicted mortality in a cohort of subjects followed for up to 11 years. After adjusting for covariates, all GOLD categories predicted a higher risk of death - GOLD stage 3 or 4: HR 5.7 (95\% CI 4.4 to 7.3); GOLD stage 2: HR 2.4 (95\% CI 2.0 to 2.9); GOLD stage $1 \mathrm{HR} 1.4$ (95\% CI 1.1 to 1.6 ); and GOLD stage O HR 1.5 (95\% CI 1.3 to 1.8 ). Ringbaek et al (7) followed 869 COPD patients and 279 asthma patients who were seeking pensions in Denmark due to disability. The standardized mortality ratios (SMR) were 3.3 (95\% CI 3.1 to 3.6) for subjects with COPD and 1.7 (95\% CI 1.4 to 2.1) for asthma patients. In another Danish study of 1075 patients with asthma who attended a chest clinic in Copenhagen (8), the RR of death was 2.4 (95\% CI 1.6 to 3.4)

${ }^{1}$ Granovsky-Gluskin Family Medicine Centre, Mount Sinai Hospital; ${ }^{2}$ Asthma and Airway Centre, University Health Network, Toronto;

${ }^{3}$ Firestone Institute for Respiratory Health, St Joseph's Healthcare, Hamilton, Ontario

Correspondence: Dr Murray Finkelstein, Granovsky-Gluskin Family Medicine Centre, Mount Sinai Hospital, Toronto, Ontario M5T 3 L9.

Telephone 416-886-6448, fax 416-736-8543, e-mail murray.finkelstein@utoronto.ca 
compared with a control group of subjects with allergy but without asthma. A study of 940 asthmatic adults drawn from a population sample of seven French cities (9) reported an RR of death of 1.48 (95\% CI 1.29 to 1.69) compared with subjects without asthma.

The aim of the present study was to investigate mortality rates among subjects attending two respiratory assessment clinics in Ontario during the 1990s, and to examine the risk factors for premature death.

\section{METHODS}

The study was approved by the Institutional Review Boards of the Hamilton Health Sciences Corporation, St Joseph's Healthcare Hamilton (Hamilton, Ontario), the University Health Network and Mount Sinai Hospital (Toronto, Ontario).

\section{Study subjects}

The cohort was initially assembled for the purpose of studying the health effects of air pollution $(10,11)$. The subjects were recruited from two academic respiratory assessment clinics in the cities of Hamilton and Toronto. The catchment area of both clinics is citywide. Individuals were referred to these clinics from the community for the diagnosis and/or management of respiratory symptoms or diseases. Subjects were identified from the lung function testing databases at each clinic. Subjects diagnosed with cancer either before or within 45 days of the initial visit were excluded. The present study was restricted to subjects 40 years of age or older because of the low mortality rate in younger individuals.

All residents of Ontario are covered under the Ontario Health Insurance Plan (OHIP), a governmental universal health insurance program. In 1992, a unique personal health insurance number (HIN) was introduced to replace a number that was family based. At each clinic, the HIN and other identifiers were collected, including residential postal codes, for all patients undergoing lung function testing between 1992 and the end of 1999. Variables abstracted from the lung function database included age, sex, height, weight and lung function testing results. Smoking information had been recorded in the electronic database at only one of the clinics; at the other clinic, examiners had collected smoking information, but this was not available in the lung function database.

Personal socioeconomic data were not available. The enumeration area (EA), with up to 440 dwellings in large urban areas, is the smallest geographic unit for which census data are available in Canada. Census data from 1996 were used to estimate the median household income by overlay of EA data onto subjects' six-character postal codes. A geographic information system and the subjects' postal codes were used to locate the subjects' residences with respect to the Hamilton and Toronto urban area road grids. Subjects residing within $50 \mathrm{~m}$ of a major urban road or within $100 \mathrm{~m}$ of a highway were considered to be exposed to traffic emissions.

Linkage to the physician OHIP billing files was used to classify underlying respiratory disease status by using diagnostic codes submitted to OHIP by specialist physicians. Subjects with diagnoses of both asthma and COPD were classified as having COPD. The OHIP billing file and the Ontario hospital discharge database were also searched for diagnoses of diabetes (International Classification of Diseases, Ninth revision [ICD9]: code 250) and chronic ischemic heart disease (IHD) (ICD9: codes 412 to 414 ) because these are confounders of mortality risk. Subjects were classified with these disorders if the diagnosis had been made in two or more claims submissions by a general practitioner, one claim submission by a specialist or during any hospitalization.

Deaths occurring between 1992 and 2002 were ascertained by linkage to the Ontario mortality registry using a probabilistic linkage algorithm based on the subjects' full names and birth dates.

\section{Statistical methods}

Mortality rates among the clinic populations were compared with those among the general population of Ontario. Ontario mortality rates, obtained from Statistics Canada, grouped in five-year age and calendar period categories, were used as the reference rates. Follow-up was terminated at 85 years of age; therefore, any deaths and years at risk after this age were not considered. SMRs - the ratio of the number of deaths observed in the study population to the number expected among subjects of the same ages in the Ontario population - were computed. CIs were computed based on the assumption that the observed deaths were distributed according to a Poisson distribution.

Poisson regression of SMRs was performed to examine the multivariate effect of risk factors on the SMRs (12). Calculations were performed using Stata software (Stata Inc, USA) (13). The results from the two clinics were combined using a random-effects meta-analysis using the 'meta' routine in the Stata software package. In a randomeffects meta-analysis, the point estimates of effect from each of the clinics are not presumed to be identical.

For internal comparisons of survival among subjects with COPD, individuals were classified according to the Global initiative for chronic Obstructive Lung Disease (GOLD) severity criteria (14) GOLD stage 1 (mild): forced expiratory volume in $1 \mathrm{~s}\left(\mathrm{FEV}_{1}\right) /$ forced vital capacity (FVC) $<0.7$ and $\mathrm{FEV}_{1} \geq 80 \%$ predicted; GOLD stage 2 (moderate): $\mathrm{FEV}_{1} / \mathrm{FVC}<0.7$, and $\mathrm{FEV}_{1} 50 \%$ to $80 \%$ predicted; GOLD stage 3 (severe): $\mathrm{FEV}_{1} / \mathrm{FVC}<0.7$ and $\mathrm{FEV}_{1} 30 \%$ to $50 \%$ predicted; and GOLD stage 4 (very severe): $\mathrm{FEV}_{1} / \mathrm{FVC}<0.7$ and $\mathrm{FEV}_{1}<30 \%$ predicted. At each clinic, subjects without a respiratory disease diagnosis were used as the comparison population, and age- and sex-adjusted survival curves were computed. Cox proportional hazards regression was used to model survival while adjusting for risk factors. The proportional hazards assumption was tested by interacting analysis time with the covariates.

\section{Study subjects}

\section{RESULTS}

Table 1 summarizes the characteristics of the study subjects according to clinic and to sex. The cohort assembled at clinic $A(n=5228)$ was larger than that from clinic B $(n=2406)$. There was a higher proportion of subjects with asthma at clinic $B$, which has a special interest in this disorder. In addition to respiratory disorders, the comorbidities of diabetes and IHD were common among subjects at both clinics. Many subjects assessed at the clinics did not have a diagnosis of either asthma or COPD: 2639 subjects at clinic A and 637 subjects from clinic B.

\section{SMRs}

The SMRs according to clinic and underlying respiratory condition are shown in Table 2. According to disease status, the mortality risks were similar at both clinics. Compared with the Ontario population average, mortality from all causes combined was approximately doubled among subjects with COPD, but was lower than expected among patients with asthma. Deaths from all malignant diseases combined were similar to the population average among subjects with COPD, but were less than the average among patients with asthma. Lung cancer mortality rates were substantially elevated among subjects diagnosed with COPD. Among the nonmalignant conditions, circulatory disease mortality was elevated by approximately $50 \%$ among subjects with COPD, and deaths attributed to respiratory disease were sixfold to sevenfold elevated compared with Ontario population rates. Among subjects with asthma, mortality attributed to respiratory diseases approximated expectations. Among subjects with asthma at clinic $A$, the five deaths attributed to respiratory disease were coded to pneumonia $(n=1)$, asthma $(n=2)$, bronchiectasis $(n=1)$ and chronic airway obstruction $(n=1)$. Among asthmatic patients at clinic $B$, the seven deaths attributed to respiratory disease were coded to pneumonia $(n=3)$, asthma $(n=1)$, chronic airway obstruction $(n=1)$ and postinflammatory pulmonary fibrosis (ICD9 code 515$)(n=2)$.

Regression analysis of age-adjusted, all-cause SMRs

Analysis of all-cause mortality was performed because of the multiple morbidities in many of the subjects. Table 3 presents the results of the 
TABLE 1

Characteristics of the study subjects

\begin{tabular}{|c|c|c|c|c|}
\hline & \multicolumn{2}{|c|}{ Clinic A } & \multicolumn{2}{|c|}{ Clinic B } \\
\hline & Women & Men & Women & Men \\
\hline $\mathrm{n}$ & 2922 & 2306 & 1260 & 1146 \\
\hline Age, years* & $49.6,60.4,70.2$ & $51.2,61.5,70.7$ & $48.2,59.8,69.6$ & $50.4,61.2,70.6$ \\
\hline Forced vital capacity, \% predicted* & $73.7,88.6,102.2$ & $66.3,81.7,95.3$ & $79.1,94.6,107.4$ & $73.0,88.6,102.3$ \\
\hline Forced expiratory volume in $1 \mathrm{~s}, \%$ predicted* & $62.9,83.6,99.1$ & $46.5,69.9,89.2$ & $67.0,85.4,101.7$ & $53.8,76.0,94.4$ \\
\hline Body mass index, $\mathrm{kg} / \mathrm{m}^{2^{\star}}$ & $24.2,28.0,32.4$ & $24.6,27.5,30.8$ & $23.2,27.6,32.1$ & $24.4,27.1,30.8$ \\
\hline Neighbourhood median household income, $\$ \times 1,000^{*}$ & $34.5,45.2,59.1$ & $34.8,47.4,60.1$ & $41.2,47.8,66.1$ & $41.0,45.9,61.3$ \\
\hline Never smokers, n/n (\%) & Not available & Not available & $841 / 1260(67)$ & $427 / 1146(37)$ \\
\hline Subjects with $\mathrm{COPD}^{\dagger}$ & $993(34)$ & $1040(45)$ & $327(26)$ & $390(34)$ \\
\hline Subjects with asthma ${ }^{\dagger}$ & $379(13)$ & $177(8)$ & $638(51)$ & $414(36)$ \\
\hline Subjects with neither COPD nor asthma ${ }^{\dagger}$ & $1550(53)$ & $1089(47)$ & $295(23)$ & $342(30)$ \\
\hline Subjects with diabetes ${ }^{\dagger}$ & 445 (15) & 395(17) & $192(15)$ & $230(20)$ \\
\hline Subjects with ischemic heart disease $^{\dagger}$ & $866(30)$ & $824(36)$ & $555(44)$ & $595(52)$ \\
\hline
\end{tabular}

${ }^{*}$ Data presented as lower quartile, median, upper quartile; ${ }^{\dagger}$ Data presented as $n(\%)$. COPD Chronic obstructive pulmonary disease

TABLE 2

Standardized mortality ratios according to cause of death

\begin{tabular}{llllll}
\hline \multirow{2}{*}{ Cause of death } & \multicolumn{2}{c}{ Clinic A } & & \multicolumn{2}{c}{ Clinic B } \\
\cline { 2 - 3 } \cline { 5 - 6 } All causes & Subjects with COPD & Subjects with asthma & & Subjects with COPD & Subjects with asthma \\
All malignancies (ICD9 codes 140-209) & $1.73(1.60-1.88) ; 623$ & $0.80(0.59-1.11) ; 38$ & & $2.13(1.85-2.45) ; 192$ & $0.73(0.56-0.96) ; 52$ \\
Lung cancer (ICD9 code 162) & $1.06(0.88-1.28) ; 110$ & $0.61(0.33-1.14) ; 10$ & & $1.22(0.86-1.72) ; 32$ & $0.69(0.42-1.13) ; 16$ \\
Circulatory diseases (ICD9 codes 390-459) & $1.93(1.46-2.55) ; 50$ & $0.25(0.04-1.75) ; 1$ & & $3.13(2.04-4.80) ; 21$ & $1.54(0.80-2.95) ; 9$ \\
Respiratory diseases (ICD9 codes 460-519) & $1.46(1.27-1.68) ; 193$ & $0.85(0.49-1.46) ; 13$ & & $1.62(1.25-2.10) ; 57$ & $0.51(0.30-0.88) ; 13$ \\
\cline { 1 - 2 } & $6.03(5.24-6.94) ; 194$ & $1.36(0.57-3.27) ; 5$ & & $7.01(5.45-9.01) ; 61$ & $1.16(0.55-2.44) ; 7$
\end{tabular}

Data presented as standardized mortality ratio (95\% Cl); number of deaths, $n$. COPD Chronic obstructive pulmonary disease; ICD 9 International Classification of Diseases, Ninth revision

\section{TABLE 3}

Regression analysis of age-adjusted, all-cause standardized mortality ratios

\begin{tabular}{|c|c|c|c|c|c|}
\hline \multirow[b]{2}{*}{ Risk factor } & \multirow[b]{2}{*}{ Level } & \multicolumn{2}{|c|}{ Subjects diagnosed with COPD } & \multicolumn{2}{|c|}{ Subjects diagnosed with asthma } \\
\hline & & Clinic A (623 deaths) & Clinic B (192 deaths) & Clinic A (38 deaths) & Clinic B (43 deaths) \\
\hline \multirow[t]{2}{*}{ Sex } & Male & 1.0 (Reference) & 1.0 (Reference) & 1.0 (Reference) & 1.0 (Reference) \\
\hline & Female & 1.27 (95\% Cl 1.08-1.49) & $1.66(95 \% \mathrm{Cl} 1.22-2.24)$ & $0.95(95 \% \mathrm{Cl} 0.48-1.90)$ & $1.42(95 \% \mathrm{Cl} 0.74-2.73)$ \\
\hline $\begin{array}{l}\text { Cigarette } \\
\text { smoking }\end{array}$ & $\begin{array}{l}\text { Per } \\
\text { pack-year }\end{array}$ & $\begin{array}{l}\text { Smoking data not recorded in } \\
\text { laboratory database }\end{array}$ & $1.004(95 \%$ Cl 1.0002-1.009) & $\begin{array}{l}\text { Smoking data not recorded in } \\
\text { laboratory database }\end{array}$ & 1.01 (95\% Cl 0.995-1.02) \\
\hline $\begin{array}{l}\text { FVC } \\
\text { (\% predicted) }\end{array}$ & $\begin{array}{l}\text { Per } 1 \% \\
\text { change }\end{array}$ & $0.983(95 \%$ Cl 0.979-0.987) & 0.977 (95\% Cl 0.970-0984) & $0.980(95 \%$ Cl 0.964-0.994) & 0.985 (95\% Cl 0.967-1.002) \\
\hline $\begin{array}{l}\mathrm{FEV}_{1} \\
\quad \text { (\% predicted) }\end{array}$ & $\begin{array}{l}\text { Per } 1 \% \\
\text { change }\end{array}$ & $\begin{array}{l}\mathrm{FEV}_{1}(\% \text { predicted) made no } \\
\text { significant contribution when } \\
\text { FVC (\% predicted) was in the } \\
\text { model }\end{array}$ & $\begin{array}{l}\mathrm{FEV}_{1} \text { (\% predicted) made no } \\
\text { significant contribution } \\
\text { when FVC (\% predicted) } \\
\text { was in the model }\end{array}$ & $\begin{array}{l}\mathrm{FEV}_{1} \text { (\% predicted) made no } \\
\text { significant contribution when } \\
\text { FVC (\% predicted) was in the } \\
\text { model }\end{array}$ & $\begin{array}{l}\mathrm{FEV}_{1} \text { ( } \% \text { predicted) made no } \\
\text { significant contribution when } \\
\text { FVC (\% predicted) was in the } \\
\text { model }\end{array}$ \\
\hline \multirow[t]{2}{*}{ BMI } & Per unit & 0.93 (95\% Cl 0.91-0.94) & $\begin{array}{l}\text { BMI made no significant } \\
\text { contribution to the model }\end{array}$ & $\begin{array}{l}\text { BMI made no significant } \\
\text { contribution to the model }\end{array}$ & $\begin{array}{l}\text { BMI made no significant } \\
\text { contribution to the model }\end{array}$ \\
\hline & BMI-squared & 1.003 (95\% Cl 1.002-1.004) & $\begin{array}{l}\text { BMI made no significant } \\
\text { contribution to the model }\end{array}$ & $\begin{array}{l}\text { BMI made no significant } \\
\text { contribution to the model }\end{array}$ & $\begin{array}{l}\text { BMI made no significant } \\
\text { contribution to the model }\end{array}$ \\
\hline \multirow{2}{*}{$\begin{array}{l}\text { Ischemic heart } \\
\text { disease }\end{array}$} & No & 1.0 (Reference) & 1.0 (Reference) & 1.0 (Reference) & 1.0 (Reference) \\
\hline & Yes & 1.13 (95\% Cl 0.96-1.33) & $1.81(95 \% \mathrm{Cl} 1.22-2.69)$ & $2.66(95 \%$ Cl 1.29-5.49) & $2.65(95 \% \mathrm{Cl} 1.19-5.92)$ \\
\hline \multirow[t]{2}{*}{ Diabetes } & No & 1.0 (Reference) & 1.0 (Reference) & $\begin{array}{l}\text { Diabetes made no significant } \\
\text { contribution to the model }\end{array}$ & $\begin{array}{l}\text { Diabetes made no significant } \\
\text { contribution to the model }\end{array}$ \\
\hline & Yes & 1.31 (95\% Cl 1.09-1.59) & $1.14(95 \% \mathrm{Cl} 0.81-1.59)$ & - & - \\
\hline $\begin{array}{l}\text { Neighbourhood } \\
\text { income }\end{array}$ & Per $\$ 10,000$ & $\begin{array}{l}\text { Neighbourhood income made } \\
\text { no significant contribution to } \\
\text { the model }\end{array}$ & $\begin{array}{l}\text { Neighbourhood income } \\
\text { made no significant } \\
\text { contribution to the model }\end{array}$ & $\begin{array}{l}\text { Neighbourhood income made } \\
\text { no significant contribution to } \\
\text { the model }\end{array}$ & $\begin{array}{l}\text { Neighbourhood income made } \\
\text { no significant contribution to } \\
\text { the model }\end{array}$ \\
\hline \multirow{2}{*}{$\begin{array}{l}\text { Residence } \\
\text { within } 50 \mathrm{~m} \text { of }\end{array}$} & No & 1.0 (Reference) & 1.0 (Reference) & 1.0 (Reference) & 1.0 (Reference) \\
\hline & Yes & $1.24(95 \%$ Cl 1.03-1.49) & $1.29(95 \% \mathrm{Cl} 0.95-1.75)$ & 1.17 (95\% Cl 0.51-2.72) & $1.94(95 \% \mathrm{Cl} 1.02-3.70)$ \\
\hline
\end{tabular}

major road or

$100 \mathrm{~m}$ of

highway

A regression coefficient <1 means that mortality risk decreased as forced vital capacity (FVC) (\% predicted) increased. BMI Body mass index; FEV 1 Forced expiratory volume in $1 \mathrm{~s}$. COPD Chronic obstructive pulmonary disease 


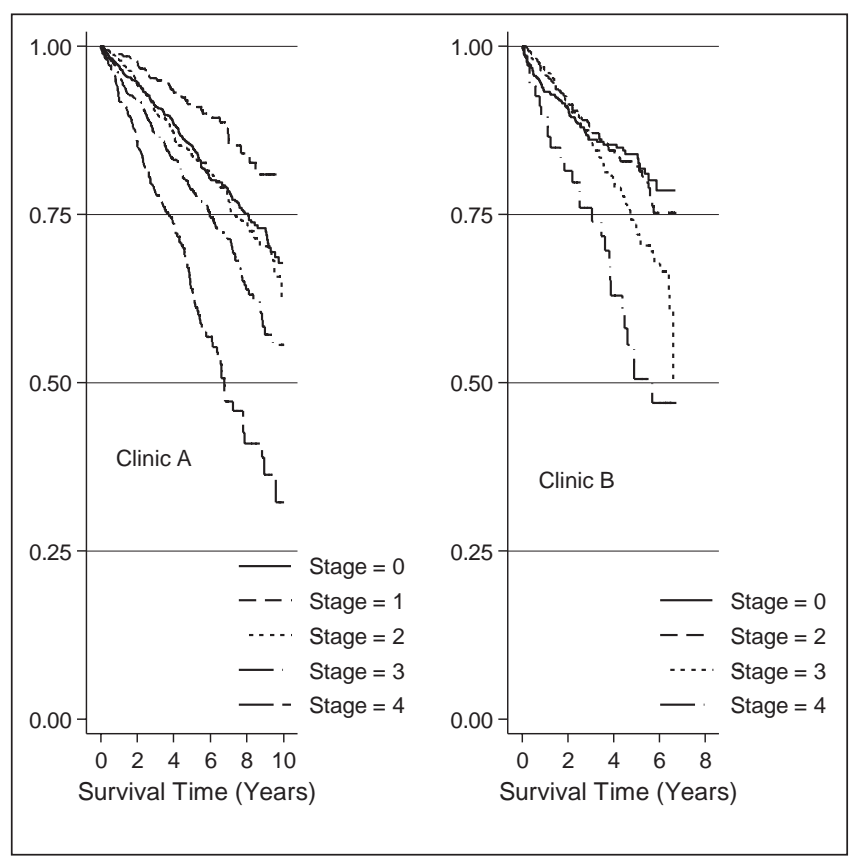

Figure 1) Probability of survival from the time of study entry in relation to the Global intitiative for chronic Obstuctive Lung Disease severity criteria. The curves have been adjusted for age and sex such that they present the risk for men 65 years of age at entry. The baseline for comparison (stage 0) are the subjects without a diagnosis of respiratory disease. The curve for stage 1 among subjects at clinic B has been suppressed because there was only one death in that group

regression analysis of age-adjusted, all-cause SMRs according to clinic and to underlying respiratory condition. Among subjects diagnosed with COPD, the risk of death adjusted for other covariates and compared with members of the general population, was significantly higher for women than for men. Smoking data were available only in the laboratory database of clinic B. Not surprisingly, the risk of death was related to the cumulative pack-years of cigarette smoking, increasing by approximately $0.5 \%$ for each pack-year. Lower measures of both FVC and $\mathrm{FEV}_{1}$ were associated with an increased risk of death. FVC and $\mathrm{FEV}_{1}$ were correlated, and when both were included in the regression model, only the effect of FVC was statistically significant. At clinic A, there was a quadratic effect of body mass index (BMI) on all-cause mortality. BMI was not significantly related to mortality at clinic B, possibly because of the lower statistical power associated with the fewer number of deaths. A concurrent diagnosis of IHD was a significant predictor of mortality among subjects with COPD or asthma. With respect to socioeconomic and environmental variables, neighbourhood income - a surrogate for personal income - showed no effect on the risk of death; however, individuals who lived closer to traffic sources demonstrated an elevated risk of death compared with those who lived further from traffic sources.

\section{Combined results}

A meta-analysis was used to combine the results from the two clinics. Mortality rates among subjects diagnosed with COPD were substantially elevated: meta-SMR 1.90 (95\% CI 1.55 to 2.33). For subjects with asthma, the all-cause meta-SMR was 0.76 (95\% CI 0.61 to 0.93). Residency close to traffic increased mortality risks for subjects with respiratory disease in each city. In the combined analysis, for subjects with COPD, the RR of death associated with residence close to traffic was 1.25 (95\% CI 1.07 to 1.47 ) and, for subjects with asthma, was 1.61 (95\% CI 0.97 to 2.68). There was no evidence of heterogeneity between the clinics $(\mathrm{P}=0.63)$.
Survival in relation to the GOLD severity criteria

Subjects with COPD were categorized according to the GOLD severity criteria defined in the Methods section (14). Age- and sex-adjusted (showing the survival of 65-year-old men) survival curves are plotted in Figure 1.

Table 4 presents the results of the full covariate-adjusted survival models in relation to GOLD stage. There was a significant trend of decreasing survival with increasing GOLD stage at clinic $\mathrm{A}$. The trend was not significant at clinic B; however, as shown in Table 4, the number of deaths in each stage were small.

\section{DISCUSSION}

We investigated the mortality pattern among subjects attending the pulmonary function laboratories associated with two academic respiratory disease clinics during the 1990s. Mortality rates among subjects diagnosed with COPD were substantially elevated, with deaths attributed to lung cancer, respiratory and circulatory causes all significantly in excess.

Among subjects with asthma, the all-causes SMR was significantly lower than expected. Despite the overall favourable survival among subjects with asthma, three deaths were attributed to asthma and two to chronic airflow obstruction, which could reflect chronic asthma.

Table 3 presented the results of a multivariate analysis of risk factors for all-cause mortality using an external reference population. For subjects with COPD, after adjusting for other risk factors, women demonstrated a higher mortality risk compared with men. It is interesting that in the analysis that used an internal comparison (Table 4), women showed a lower risk than men. This may be interpreted to mean that, among subjects with COPD, the prognosis of women is better than that of men, but when compared with a largely disease-free population, women are at higher risk than men, probably due to the higher overall mortality rates of men in the general population.

As expected, cigarette smoking history and poorer lung function test results were significant predictors of increased mortality risk. The relationships between survival and the GOLD severity classification were shown in Figure 1, and graphically illustrate the relationships presented in Table 4.

The comorbidities of circulatory disease and diabetes were highly prevalent among subjects with COPD, and significantly contributed to mortality risk. A study from the United Kingdom-based General Practice Research Database (15) recently reported that the incidence of cardiovascular diseases was higher among patients diagnosed with COPD. Thus, patients with COPD need to be managed with attention devoted to both their respiratory disorders and related comorbidities. Several strategies are available. Physicians often avoid the use of $\beta$-blockers in patients with COPD and concurrent cardiovascular disease because of concerns about adverse pulmonary effects (16). A recent observational cohort study in the Netherlands (17) reported, however, that treatment with $\beta$-blockers may reduce the risk of exacerbations and improve survival in patients with COPD, possibly as a result of dual cardiopulmonary protective properties.

Statins are another class of medications that may prove to be of value. Young et al (18) noted, "evidence shows statins have important anti-inflammatory effects in both the lungs and arteries. Although randomized control trials are yet to be reported, nonrandomized studies have consistently shown benefit in COPD patients taking statins compared with those not. These include reductions in both cardiovascular and respiratory morbidity/mortality". A nonrandomized study conducted in Norway (19), for example, reported that the HR for allcause mortality among 854 consecutive patients discharged from hospital with a diagnosis of COPD exacerbation was 0.57 (95\% CI 0.38 to 0.87) among statin users versus nonusers.

It has also been suggested that inhaled medications, in particular inhaled corticosteroids, not only reduce airway inflammation but may also reduce systemic inflammation and consequent cardiovascular sequelae (20-23).

While these medications may provide benefit, there has been some concern that commonly prescribed treatments, such as long-acting 
TABLE 4

Proportional hazards regression analysis of age-adjusted, all-cause mortality in relation to Global initiative for chronic Obstructive Lung Disease (GOLD) severity stages

\begin{tabular}{|c|c|c|c|}
\hline Risk factor & Level & Clinic $A^{*}$ & Clinic B* \\
\hline \multirow[t]{2}{*}{ Sex } & Male & 1.0 (Reference) & 1.0 (Reference) \\
\hline & Female & $0.63(0.53-0.74)$ & $0.84(0.61-1.15)$ \\
\hline Cigarette smoking & Per pack-year & Smoking data not recorded in laboratory database & $1.01(1.006-1.016)$ \\
\hline Body mass index & Per unit & $0.93(0.91-0.94)$ & $0.78(0.70-0.88)$ \\
\hline Body mass index-squared & & $1.003(1.002-1.004)$ & $1.004(1.002-1.006)$ \\
\hline \multirow[t]{2}{*}{ Ischemic heart disease } & No & 1.0 (Reference) & 1.0 (Reference) \\
\hline & Yes & $1.20(1.03-1.40)$ & $1.78(1.26-2.51)$ \\
\hline \multirow[t]{2}{*}{ Diabetes } & No & 1.0 (Reference) & 1.0 (Reference) \\
\hline & Yes & $1.44(1.20-1.73)$ & $1.24(0.87-1.77)$ \\
\hline Neighbourhood income & Per $\$ 10,000$ & $0.96(0.92-0.99)$ & $0.98(0.88-1.09)$ \\
\hline \multirow{2}{*}{$\begin{array}{l}\text { Residence within } 50 \mathrm{~m} \text { of major } \\
\text { road or } 100 \mathrm{~m} \text { of highway }\end{array}$} & No & 1.0 (Reference) & 1.0 (Reference) \\
\hline & Yes & $1.28(1.07-1.52)$ & $1.38(1.02-1.88)$ \\
\hline \multirow[t]{6}{*}{ GOLD stage $^{\dagger}$} & Subjects without respiratory diagnosis & 1.0 (Reference); 281 & 1.0 (Reference); 73 \\
\hline & GOLD stage 1 & $1.13(0.80-1.60) ; 40$ & $0.12(0.02-0.87) ; 1$ \\
\hline & GOLD stage 2 & 1.55 (1.23-1.96); 103 & 0.90 (0.61-1.33); 47 \\
\hline & GOLD stage 3 & 1.61 (1.31-1.98); 148 & 1.02 (0.70-1.49); 65 \\
\hline & GOLD stage 4 & 2.28 (1.82-2.86); 141 & 1.81 (1.12-2.94); 27 \\
\hline & Test for trend & $P<0.01$ & $P=0.12$ \\
\hline
\end{tabular}

${ }^{*}$ The reference group was comprised of subjects without a diagnosis of respiratory disease, data presented as HR (95\% CI); ${ }^{\dagger}$ Data presented as $\mathrm{HR}(95 \% \mathrm{Cl})$; number of deaths, $n$

$\beta$-agonists, may increase the risk of cardiovascular events. A recent post hoc analysis of the data set from the Towards a Revolution in COPD Health (TORCH) trial (24) reported that the use of salmeterol did not increase the risk of cardiovascular events in patients with moderate to severe COPD.

We also explored several socioeconomic and environmental variables as risk factors for premature mortality. We found no significant association between socioeconomic status, as measured by neighbourhood income and mortality. As previously reported $(11,25)$, there was an association between residency close to traffic and increased mortality risk. In the combined analysis of the two clinics, the RR of death associated with residence close to traffic was 1.25 (95\% CI 1.07 to 1.47 ) for subjects with COPD, and 1.61 (95\% CI 0.97 to 2.68) for subjects with asthma. Efforts to reduce community air pollution levels should, thus, prove to be of benefit to subjects with respiratory disease.

\section{SUMMARY}

We found that subjects with COPD seen at two Ontario pulmonary function laboratories during the 1990s demonstrated a substantially increased mortality risk attributable to excess mortality from lung cancer, and respiratory and circulatory diseases. These subjects were also vulnerable to the effects of traffic-related air pollution. Subjects with COPD frequently have other morbidities, and attention should be paid to managing the total risk.

In contrast, subjects with asthma experienced lower than average mortality risk. This is consistent with the old adage about asthmatic patients 'panting into old age'. It is possible that asthma patients may be less likely than others to smoke. At clinic B, 32 (6\%) of 562 men and $36(4 \%)$ of 858 women with asthma reported that they were current smokers. A more recent suggestion is that the use of inhaled corticosteroids in modern treatment may reduce systemic inflammation and its consequences (26), which might explain the lower mortality observed in this study compared with the earlier European studies. Despite the lower overall mortality risk, several deaths among patients with asthma were attributed to asthma and chronic airflow obstruction. For the minority of individuals with asthma, the disease may still have fatal consequences.
COMPETING INTERESTS: The authors have no competing interests to declare.

FUNDING: This work was funded by a grant from the Canadian Institutes of Health Research.

\section{REFERENCES}

1. Public Health Agency of Canada. Life and Breath: Respiratory Disease in Canada, 2007. Ottawa: Ministry of Health, 2007.

2. Hill K, Goldstein RS, Guyatt GH, et al. Prevalence and underdiagnosis of chronic obstructive pulmonary disease among patients at risk in primary care. CMAJ 2010;182:673-8.

3. Bednarek M, Maciejewski J, Wozniak M, Kuca P, Zielinski J. Prevalence, severity and underdiagnosis of COPD in the primary care setting. Thorax 2008;63:402-7.

4. Murray CJ, Lopez AD. Alternative projections of mortality and disability by cause 1990-2020: Global Burden of Disease Study. Lancet 1997;349:1498-504.

5. Anthonisen NR, Wright EC, Hodgkin JE. Prognosis in chronic obstructive pulmonary disease. Am Rev Respir Dis 1986;133:14-20.

6. Mannino DM, Doherty DE, Sonia BA. Global Initiative on Obstructive Lung Disease (GOLD) classification of lung disease and mortality: Findings from the Atherosclerosis Risk in Communities (ARIC) study. Respir Med 2006;100:115-22.

7. Ringbaek T, Seersholm N, Viskum K. Standardised mortality rates in females and males with COPD and asthma. Eur Respir J 2005;25:891-5.

8. Ulrik CS, Frederiksen J. Mortality and markers of risk of asthma death among 1,075 outpatients with asthma. Chest 1995;108:10-5.

9. Vandentorren S, Baldi I, Annesi M, et al. Long-term mortality among adults with or without asthma in the PAARC study. Eur Respir J 2003;21:462-7.

10. Finkelstein MM, Jerrett M, DeLuca P, et al. Relation between income, air pollution and mortality: A cohort study. CMAJ 2003;169:397-402.

11. Jerrett M, Finkelstein MM, Brook JR, et al. A cohort study of traffic-related air pollution and mortality in Toronto, Ontario, Canada. Environ Health Perspect 2009;117:772-7. 
12. Yasui Y, Liu Y, Neglia JP, et al. A methodological issue in the analysis of second-primary cancer incidence in long-term survivors of childhood cancers. Am J Epidemiol 2003;158:1108-13.

13. Stata Statistical Software. Version 11.0. College Station, Texas: Stata Corporation; 2009.

14. Pauwels RA, Buist AS, Calverley PM, Jenkins CR, Hurd SS. Global strategy for the diagnosis, management, and prevention of chronic obstructive pulmonary disease. NHLBI/WHO Global Initiative for Chronic Obstructive Lung Disease (GOLD) Workshop summary. Am J Respir Crit Care Med 2001;163:1256-76.

15. Schneider C, Bothner U, Jick SS, Meier CR. Chronic obstructive pulmonary disease and the risk of cardiovascular diseases. Eur J Epidemiol 2010;25:253-60.

16. Sin DD, Man SF. A curious case of beta-blockers in chronic obstructive pulmonary disease. Arch Intern Med 2010;170:849-50.

17. Rutten FH, Zuithoff NP, Hak E, Grobbee DE, Hoes AW. Beta-blockers may reduce mortality and risk of exacerbations in patients with chronic obstructive pulmonary disease. Arch Intern Med 2010;170:880-7.

18. Young RP, Hopkins R, Eaton TE. Potential benefits of statins on morbidity and mortality in chronic obstructive pulmonary disease: A review of the evidence. Postgrad Med J 2009;85:414-21.
19. Soyseth V, Brekke PH, Smith P, Omland T. Statin use is associated with reduced mortality in COPD. Eur Respir J 2007;29:279-83.

20. Sin DD, Lacy P, York E, Man SF. Effects of fluticasone on systemic markers of inflammation in chronic obstructive pulmonary disease. Am J Respir Crit Care Med 2004;170:760-5.

21. Sin DD, Wu L, Anderson JA, et al. Inhaled corticosteroids and mortality in chronic obstructive pulmonary disease. Thorax 2005;60:992-7.

22. Gan WQ, Man SF, Sin DD. Effects of inhaled corticosteroids on sputum cell counts in stable chronic obstructive pulmonary disease: A systematic review and a meta-analysis. BMC Pulm Med 2005;5:3.

23. Sin DD, Man SF. Chronic obstructive pulmonary disease as a risk factor for cardiovascular morbidity and mortality. Proc Am Thorac Soc 2005;2:8-11.

24. Calverley PM, Anderson JA, Celli B, et al. Cardiovascular events in patients with COPD: TORCH study results. Thorax 2010;65:719-25.

25. Finkelstein MM, Jerrett M, Sears MR. Traffic air pollution and mortality rate advancement periods. Am J Epidemiol 2004;160:173-7.

26. Camargo CA Jr, Barr RG, Chen R, Speizer FE. Prospective study of inhaled corticosteroid use, cardiovascular mortality, and all-cause mortality in asthmatic women. Chest 2008;134:546-51. 


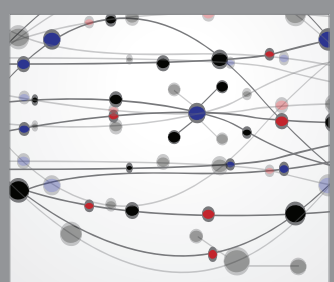

The Scientific World Journal
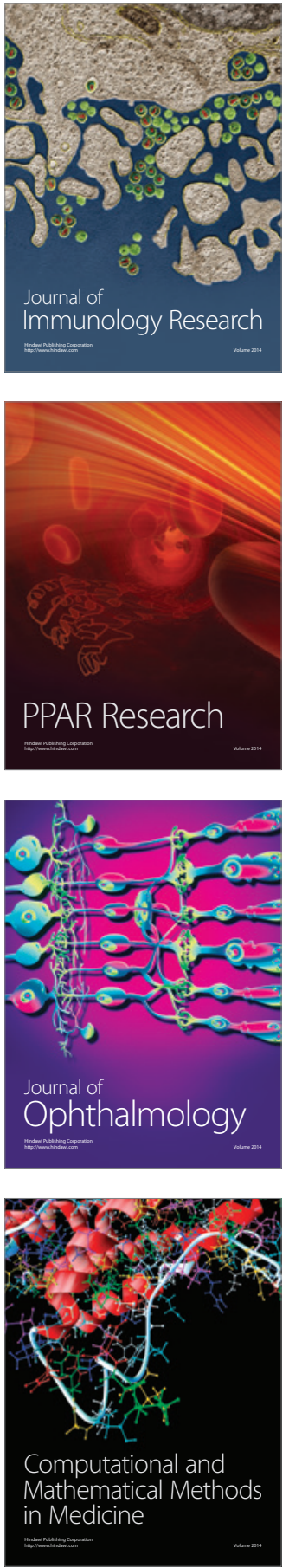

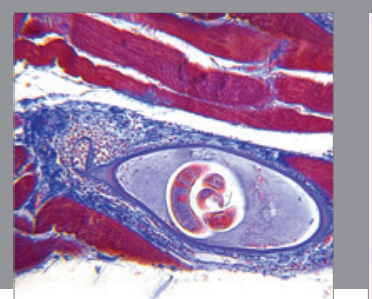

Gastroenterology Research and Practice

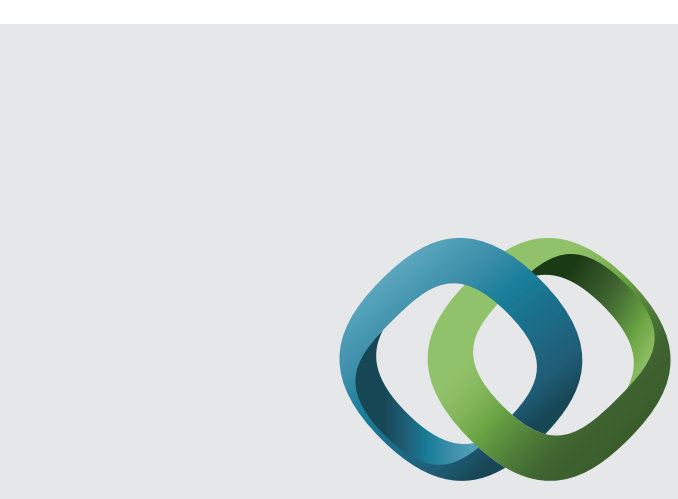

\section{Hindawi}

Submit your manuscripts at

http://www.hindawi.com
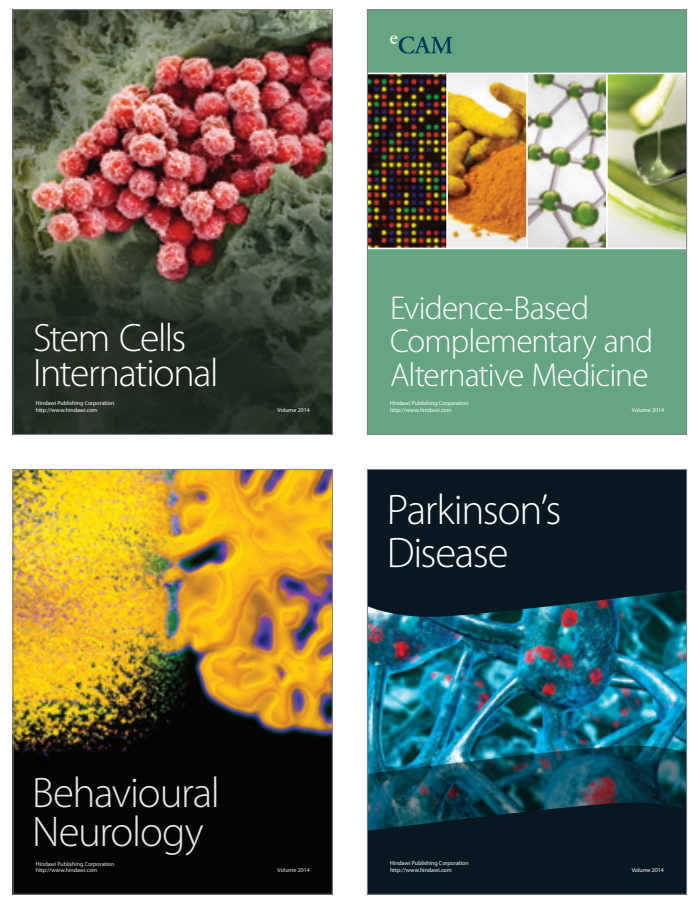
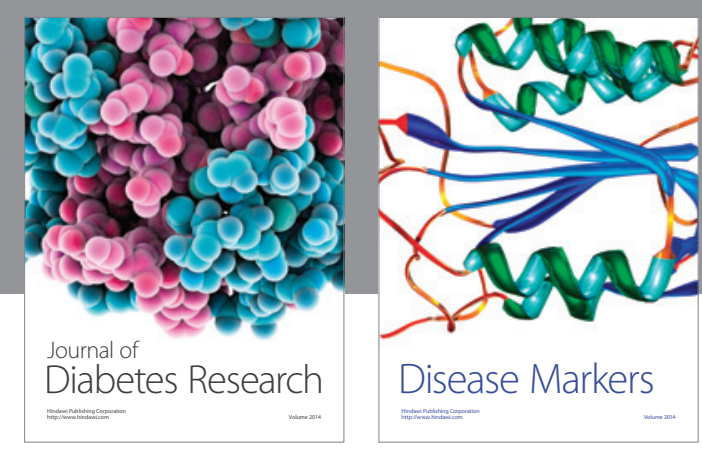

Disease Markers
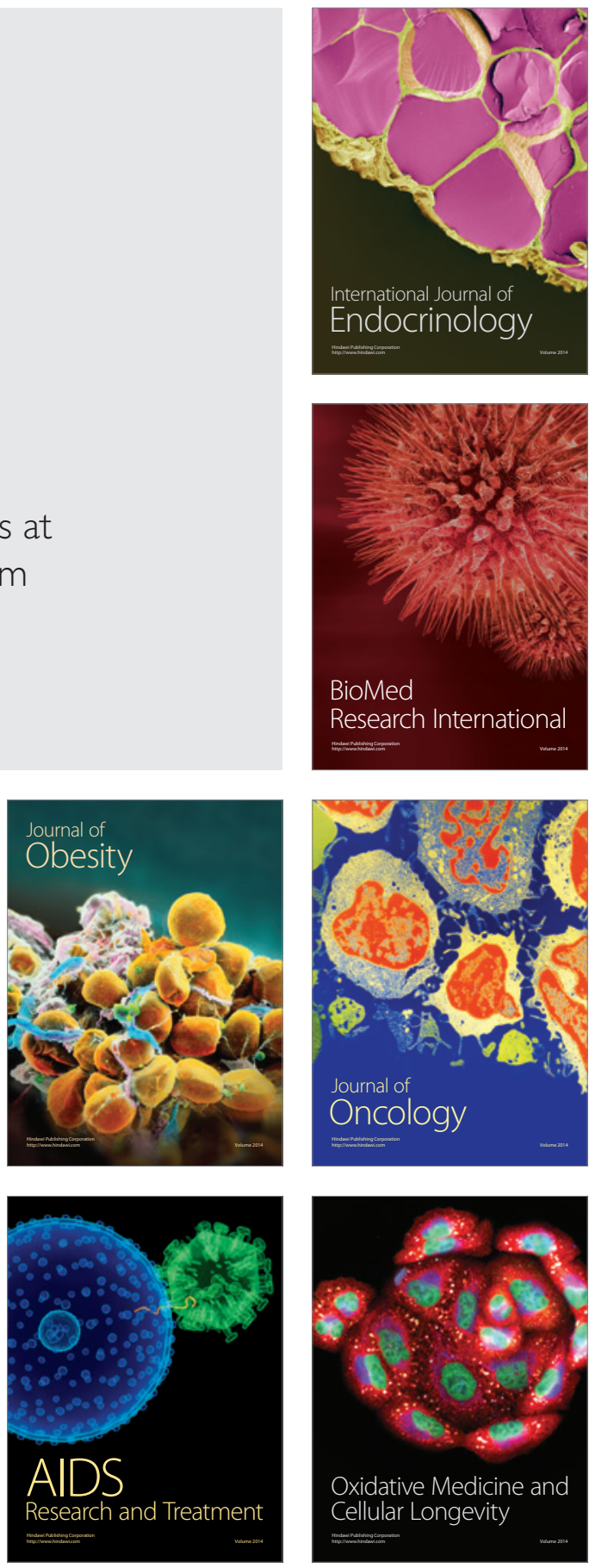